\title{
ChemComm
}

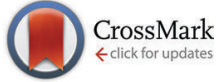

Cite this: Chem. Commun., 2015, 51,892

Received 16th October 2014, Accepted 20th November 2014

DOI: $10.1039 / \mathrm{c} 4 \mathrm{cc} 08211 \mathrm{~g}$

www.rsc.org/chemcomm

\section{Intramolecular hydroalkoxylation catalyzed inside a self-assembled cavity of an enzyme-like host structure $\dagger$}

\author{
L. Catti and K. Tiefenbacher*
}

\begin{abstract}
Self-assembled resorcin[4]arene hexamer catalyzes the intramolecular hydroalkoxylation of unsaturated alcohols to the corresponding cyclic ethers under mild conditions. The mode of catalysis and encapsulationbased substrate selectivity of the host efficiently mimic the basic principle of operation observed in enzymes.
\end{abstract}

Supramolecular catalysis aims to mimic the functions of enzymes without copying the complexity of their evolutionarily derived three-dimensional structure. Key features of enzyme catalysis comprise the selection of suitable substrates inside a hydrophobic reaction pocket, the altering of substrate orientation and/or conformation and the stabilization of the transition state of the reaction. ${ }^{1}$ In the last two decades, research in the field of supramolecular chemistry has led to the preparation of a variety of self-assembled hosts bearing an internal cavity, which provides a defined chemical environment distinct from the bulk solvent. ${ }^{1,2}$ Application of a subset of noncovalently self-assembled structures to catalysis was successfully investigated by several groups. ${ }^{1,2 d, f, 3}$ However, the use of hydrogen bond-based assemblies in catalysis is limited to only five examples reported in literature. ${ }^{3 f, 4}$

The resorcin[4]arene hexamer I (Fig. 1) represents one of the largest hydrogen bond-based self-assembled hosts and has been studied intensively due to its ready accessibility. ${ }^{5}$ It spontaneously forms in apolar solvents like chloroform and benzene from six resorcin[4]arene units $\mathbf{1}$, which are easily prepared in multigram scale in a single step. In addition to the six monomer units, eight water molecules participate in the formation of the hexamer, ${ }^{6}$ which explains the excessive use of water-saturated solvents in resorcin[4]arene chemistry. ${ }^{2 a, 7}$ The capsule-like structure, held together by 60 hydrogen bonds, forms an octahedral-shaped cavity of about $1375 \AA^{3} .^{5 a}$ In chloroform solution, this cavity is occupied by six solvent molecules in the absence of suitable guests. ${ }^{8}$ Due to extended cation $-\pi$ interactions with the aromatic cavity, positive

Department Chemie, Technische Universität München, Lichtenbergstraße 4, D-85747 Garching, Germany. E-mail: konrad.tiefenbacher@tum.de $\dagger$ Electronic supplementary information (ESI) available: Experimental details, characterization data and NMR spectra. See DOI: 10.1039/c4cc08211g

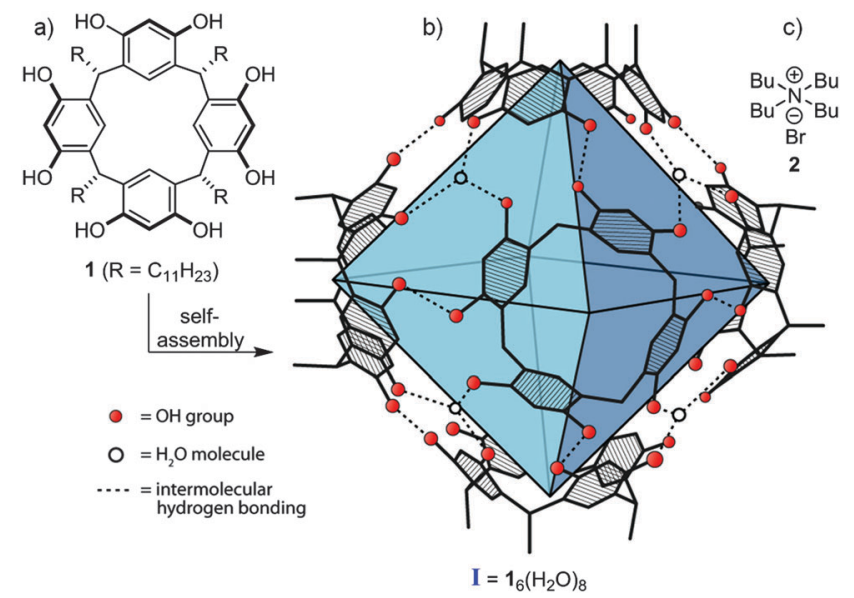

Fig. 1 (a) Structure of resorcin[4]arene 1; (b) schematic representation of the hexameric resorcin[4]arene capsule I, emphasizing the octahedral cavity space (blue); alkyl groups have been omitted for clarity; (c) competitive inhibitor tetrabutylammonium bromide $\left(\mathrm{Bu}_{4} \mathrm{NBr}\right)(\mathbf{2})$.

charged compounds like quaternary ammonium ions (e.g. 2) display a high affinity for the capsule interior. ${ }^{9}$ Other suitable guests like alcohols and carboxylic acids rely on their ability to form hydrogen bonds with the hexameric host and, depending on their size, are coencapsulated with residual solvent molecules. ${ }^{7,10}$ Besides the capability of reversible guest encapsulation, the resorcin[4]arene hexamer acts as relatively strong phenol-based Brønsted acid ( $\left.\mathrm{p} K_{\mathrm{a}} \approx 5.5-6\right)$, as recently reported by our group, ${ }^{3 f}$ making it an appropriate choice for the study of enzyme-like acid catalysis.

Being aware of the good uptake of certain alcohol molecules, ${ }^{10 \mathrm{~b}}$ we set out to explore the potential use of $\mathbf{I}$ as an acid catalyst in the intramolecular hydroalkoxylation of unactivated hydroxy olefins. Intramolecular hydroalkoxylation offers a direct, atom-economical access to cyclic ethers, which represent important core structures frequently found in polyether antibiotics, marine macrocycles and flavor compounds. ${ }^{11}$ Although the cationic intramolecular hydroalkoxylation of unsaturated alcohols has been reported to be catalyzed by strong Brønsted acids like triflic acid (TfOH), ${ }^{12}$ 
poor functional group compatibility, acid induced side reactions and the overall harsh reaction conditions limit the scope of these protocols. The application of weaker acids on the other hand often requires the use of over-stoichiometric amounts. ${ }^{13}$ Alternative catalytic approaches include the utilization of Lewis super-acids like $\mathrm{Al}(\mathrm{OTf})_{3}{ }^{14}$ and $\mathrm{Ca}\left(\mathrm{NTf}_{2}\right)_{2},{ }^{15}$ transition metals, ${ }^{16}$ zeolites $^{17}$ and Amberlyst $\mathrm{H}-15 .^{18}$ In the context of supramolecular catalysis, Bergman, Raymond and Toste investigated the intramolecular hydroalkoxylation of activated hydroxy olefins inside a supramolecular host using an encapsulated gold catalyst. ${ }^{19}$

We began our investigation by adding 10 equiv. of hydroxy olefin 3a (Table 1) to a solution of I (1 equiv.) in water-saturated $\mathrm{CDCl}_{3}(3.3 \mathrm{mM})$. The appearance of new upfield-shifted signals

Table 1 Intramolecular hydroalkoxylation of unactivated hydroxy olefins ${ }^{a}$

(Time (d))

$3 \mathbf{j}$

$4 \mathbf{j}$

${ }^{a}$ Reaction conditions: hydroxy olefin $(33 \mathrm{mM})$, catalyst I (3.3 $\left.\mathrm{mM}\right)$, $\mathrm{CDCl}_{3}, 30{ }^{\circ} \mathrm{C}, 0.7-6 \mathrm{~d}^{b}{ }^{b}$ Determined via ${ }^{1} \mathrm{H}$ NMR. ${ }^{c}$ Determined via GC (response factor-corrected). in the region of 0.5 to $-0.6 \mathrm{ppm}$ in the ${ }^{1} \mathrm{H}$ NMR spectrum of the reaction mixture, caused by the anisotropy of the capsule walls, indicated encapsulation of substrate 3a. Reaction monitoring via NMR spectroscopy and GC and finally isolation confirmed selective conversion to cyclic ether 4a. A subsequent optimization of the reaction conditions revealed the influence of water content and substrate concentration on the reaction rate. Reducing the water content of the reaction mixture from 30 equiv. to 11 equiv. of water per hexamer I (determined via ${ }^{1} \mathrm{H}$ NMR spectroscopy) by utilizing regular $\mathrm{CDCl}_{3}$ instead of water-saturated $\mathrm{CDCl}_{3}$ resulted in a significant increase in the reaction rate. It seems likely that the water molecules compete with the substrate for the protons of the catalyst. High substrate concentration on the other hand lead to a drastic decrease of the reaction rate, since the hydroxyl group of the substrate can interact with the monomer units and thereby reduce the equilibrium concentration of operational catalyst. ${ }^{9}$ Applying the optimized conditions, full conversion of substrate 3a was achieved after about $3.5 \mathrm{~d}$ at $30{ }^{\circ} \mathrm{C}$. In a control experiment, a small excess of the high affinity guest $\mathrm{Bu}_{4} \mathrm{NBr}$ (2) (1.5 equiv.) was added to the catalyst solution prior to substrate addition. When catalyst I was blocked in this manner, the hydroalkoxylation of alcohol 3a was efficiently slowed down, giving only a weak background conversion of $7 \%$. A second control experiment without added catalyst was performed to rule out a background reaction catalyzed by trace amounts of $\mathrm{HCl} / \mathrm{DCl}$, potentially formed by photodegradation of $\mathrm{CDCl}_{3}$. In this case, no detectable conversion was observed after $7 \mathrm{~d}$. These results demonstrated that a catalytic conversion is indeed possible with $\mathbf{I}$ and that the reaction takes place inside the cavity after initial protonation of the substrate. The observed catalytic effect imparted by hexamer I is believed to result from the stabilization of cationic intermediates and transitions states by cation- $\pi$ interactions with the aromatic cavity. The catalytic cycle is finally completed by release of the cyclic ether, which does not bind strongly to the cavity.

In order to evaluate the scope of the hexamer I-catalyzed intramolecular hydroalkoxylation, we next investigated the formation of differently substituted tetrahydropyran and oxepane derivatives as summarized in Table 1 . In general, the reactions proceeded to completion in 0.7 to $6 \mathrm{~d}$ at $30{ }^{\circ} \mathrm{C}$ using a $10 \mathrm{~mol} \%$ catalyst loading. Conversion of $\gamma, \delta$-unsaturated monoalcohols gave the corresponding tetrahydropyran derivatives in good yields (Table 1, entries 1-4). When employing substrates bearing two hydroxyl groups, full conversion was achieved within $16 \mathrm{~h}$, owing to the high affinity of diols to the capsule interior (Table 1, entries 5 and 6). In the case of substrate $3 g$, a reduced yield was obtained, presumably due to an oligomerization side reaction, as implied by broad signals in the ${ }^{1} \mathrm{H}$ NMR spectrum. Meanwhile, the formation of oxepane $\mathbf{4 h}$ proceeded in good yield. However, when a terminal olefin was used, the reaction proceeded much slower with GC indicating intermediary formation of the corresponding trisubstituted and hydrated olefin (Table 1, entry 9). The spirobicyclic ether $\mathbf{4 j}$ was obtained in $63 \%$. The reduced yield is based on an equilibrium between starting material and cyclization product, as proven by subjecting the isolated ether to standard reaction conditions. All performed hydroalkoxylations occurred with Markovnikov selectivity. Furthermore, all substrates were tested with $\mathrm{Bu}_{4} \mathrm{NBr}$ (2)-inhibited catalyst, giving only a weak background reaction in each case (Table 1). Catalyst I was also 


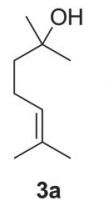

(5 equiv)



5

(5 equiv)
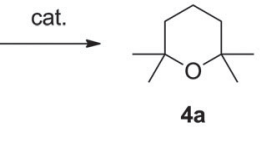

$4 a$

\begin{tabular}{llll}
\multicolumn{1}{c}{ cat. } & time & conv. & $\begin{array}{c}\text { ratio } \\
\text { of conv. }\end{array}$ \\
\hline $10 \mathrm{~mol} \% \mathrm{TfOH}$ & $7 \mathrm{~h}$ & $67 \%$ & $46: 54$ \\
$10 \mathrm{~mol} \% \mathrm{I}$ & $64 \mathrm{~h}$ & $53 \%$ & $92: 8$
\end{tabular}

Fig. 2 Substrate selectivity imposed by hexamer $\mathbf{I}$.

successfully applied for the synthesis of tetrahydrofuran derivatives. However, in those cases, an increased background reaction was observed, caused by the high reactivity of the employed starting materials. On the other hand, substrates that would require the formation of an intermediary secondary cation showed no reactivity under the reaction conditions (see ESI, $\dagger$ chapter 10).

After having demonstrated the applicability of hexamer I as a catalyst in intramolecular hydroalkoxylations, we next tried to explore the possibility of selectively converting one hydroxy olefin in the presence of another. Indeed, when adding a mixture of $\mathbf{3 a}$ and $\mathbf{5}$ (5 equiv. each; Fig. 2) to a solution of $\mathbf{I}$ (1 equiv.) in $\mathrm{CDCl}_{3}(3.3 \mathrm{mM})$, the reaction proceeded in a highly selective fashion: After $64 \mathrm{~h}$, the small substrate was almost completely converted (98\%), while the large analogue showed only $8 \%$ conversion. This corresponds to a $92: 8$ ratio of conversion. The slow transformation of the large hydroxy olefin 5 can be explained by its decreased uptake. This observation correlates to previous findings regarding the hydrolysis rate of acetals utilizing hexamer $\mathbf{I} .^{3 f}$ As a control experiment, capsule I was replaced with $10 \mathrm{~mol} \%$ of $\mathrm{TfOH}\left(\mathrm{p} K_{\mathrm{a}}=-12\right.$; in water), ${ }^{20}$ since use of $10 \mathrm{~mol} \%$ of a weaker reagent like acetic acid $\left(\mathrm{p} K_{\mathrm{a}}=\right.$ 4.8 ; in water $)^{20}$ did not provide any conversion in the case of substrate $\mathbf{3 b}$ after $3 \mathrm{~d}$. As expected, conversion to the cyclic ethers $4 \mathbf{a}$ and $\mathbf{6}$ proceeded unselectively and less cleanly, resulting in $61 \%$ conversion of $3 \mathbf{a}$ and $72 \%$ conversion of 5 after $7 \mathrm{~h}$ (ratio of $46: 54$ ). This experiment successfully demonstrated the selectivity imposed by hexamer $\mathbf{I}$ in a reaction that is very hard to control in bulk solution.

We herein presented the application of hexameric capsule I as a catalyst in the intramolecular hydroalkoxylation of unactivated hydroxy olefins under mild conditions. Evidence was provided that the reactions proceed inside the self-assembled cavity upon encapsulation of the substrate. These findings were successfully translated into substrate selectivity when a mixture of differently sized olefins was employed. Thus, the unique properties of hexamer I, including its large internal cavity, its acidic nature and its ability to undergo strong cation $-\pi$ interactions were efficiently utilized to mimic basic properties of enzyme catalysis.

This project was supported by the "Bayerische Akademie der Wissenschaften" (Junges Kolleg), "Fonds der Chemischen Industrie" (Sachkostenzuschuss), the TUM Junior Fellow Fund and the "Dr-Ing. Leonhard-Lorenz-Stiftung". The help of MSc Johannes Richers with graphical design is greatly acknowledged.
Furthermore, we thank Dr Thomas Magauer and MSc Klaus Speck for help with HRMS measurements.

\section{Notes and references}

1 (a) T. S. Koblenz, J. Wassenaar and J. N. H. Reek, Chem. Soc. Rev., 2008, 37, 247-262; (b) M. J. Wiester, P. A. Ulmann and C. A. Mirkin, Angew. Chem., Int. Ed., 2011, 50, 114-137; (c) M. Raynal, P. Ballester, A. Vidal-Ferran and P. W. N. M. van Leeuwen, Chem. Soc. Rev., 2014, 43, 1734-1787.

2 (a) F. Hof, S. L. Craig, C. Nuckolls and J. J. Rebek, Angew. Chem., Int. Ed., 2002, 41, 1488-1508; (b) L. C. Palmer and J. J. Rebek, Org. Biomol. Chem., 2004, 2, 3051-3059; (c) J. Rebek, Acc. Chem. Res., 2009, 42, 1660-1668; (d) M. Yoshizawa, J. K. Klosterman and M. Fujita, Angew. Chem., Int. Ed., 2009, 48, 3418-3438; (e) D. Ajami and J. Rebek, Acc. Chem. Res., 2012, 46, 990-999; $(f)$ S. Zarra, D. M. Wood, D. A. Roberts and J. R. Nitschke, Chem. Soc. Rev., 2014, DOI: 10.1039/C4CS00165F; $(g)$ J. H. Jordan and B. C. Gibb, Chem. Soc. Rev., 2014, DOI: 10.1039/C4CS00191E.

3 For recent examples, see: (a) V. Bocokić, A. Kalkan, M. Lutz, A. L. Spek, D. T. Gryko and J. N. H. Reek, Nat. Commun., 2013, 4, 2670, DOI: 10.1038/ ncomms3670; (b) P. Dydio, R. J. Detz and J. N. H. Reek, J. Am. Chem. Soc., 2013, 135, 10817-10828; (c) A. G. Salles, S. Zarra, R. M. Turner and J. R. Nitschke, J. Am. Chem. Soc., 2013, 135, 19143-19146; (d) Z. J. Wang, K. N. Clary, R. G. Bergman, K. N. Raymond and F. D. Toste, Nat. Chem., 2013, 5, 100-103; (e) C. Zhao, Q.-F. Sun, W. M. Hart-Cooper, A. G. DiPasquale, F. D. Toste, R. G. Bergman and K. N. Raymond, J. Am. Chem. Soc., 2013, 135, 18802-18805; $(f)$ Q. Zhang and K. Tiefenbacher, J. Am. Chem. Soc., 2013, 135, 16213-16219; $(g)$ P. Jagadesan, B. Mondal, A. Parthasarathy, V. J. Rao and V. Ramamurthy, Org. Lett., 2013, 15, 1326-1329; (h) R. Kulasekharan, M. V. S. N. Maddipatla, A. Parthasarathy and V. Ramamurthy, J. Org. Chem., 2013, 78, 942-949.

4 (a) J. Kang, J. Santamaría, G. Hilmersson and J. Rebek, J. Am. Chem. Soc., 1998, 120, 7389-7390; (b) A. Cavarzan, A. Scarso, P. Sgarbossa, G. Strukul and J. N. H. Reek, J. Am. Chem. Soc., 2011, 133, 2848-2851; (c) G. Bianchini, G. La Sorella, N. Canever, A. Scarso and G. Strukul, Chem. Commun., 2013, 49, 5322-5324; (d) S. Shimizu, A. Usui, M. Sugai, Y. Suematsu, S. Shirakawa and H. Ichikawa, Eur. J. Org. Chem., 2013, 4734-4737.

5 (a) L. R. MacGillivray and J. L. Atwood, Nature, 1997, 389, 469-472; (b) L. Avram, Y. Cohen and J. Rebek, Chem. Commun., 2011, 47, 5368-5375.

6 L. Avram and Y. Cohen, Org. Lett., 2002, 4, 4365-4368.

7 T. Evan-Salem, I. Baruch, L. Avram, Y. Cohen, L. C. Palmer and J. Rebek, Proc. Natl. Acad. Sci. U. S. A., 2006, 103, 12296-12300.

8 A. Shivanyuk and J. Rebek, J. Am. Chem. Soc., 2003, 125, 3432-3433.

9 L. Avram and Y. Cohen, J. Am. Chem. Soc., 2004, 126, 11556-11563.

10 (a) L. Avram and Y. Cohen, J. Am. Chem. Soc., 2002, 124, 15148-15149; (b) S. Slovak and Y. Cohen, Chem. - Eur. J., 2012, 18, $8515-8520$.

11 M. C. Elliott and E. Williams, J. Chem. Soc., Perkin Trans. 1, 2001, 2303-2340.

12 D. C. Rosenfeld, S. Shekhar, A. Takemiya, M. Utsunomiya and J. F. Hartwig, Org. Lett., 2006, 8, 4179-4182.

13 (a) G. Carr and D. Whittaker, J. Chem. Soc., Perkin Trans. 2, 1989, 359-366; (b) P. J. Linares-Palomino, S. a. Salido, J. n. Altarejos and A. Sánchez, Tetrahedron Lett., 2003, 44, 6651-6655.

14 L. Coulombel, M. Rajzmann, J.-M. Pons, S. Olivero and E. Duñach, Chem. - Eur. J., 2006, 12, 6356-6365.

15 A. Kena Diba, J.-M. Begouin and M. Niggemann, Tetrahedron Lett., 2012, 53, 6629-6632.

16 H. Qian, X. Han and R. A. Widenhoefer, J. Am. Chem. Soc., 2004, 126, 9536-9537.

17 E. Pérez-Mayoral, I. Matos, P. Nachtigall, M. Položij, I. Fonseca, D. Vitvarová-Procházková and J. Čejka, ChemSusChem, 2013, 6, 1021-1030.

18 S. A. Singh, S. Kabiraj, R. P. Khandare, S. P. Nalawade, K. B. Upar and S. V. Bhat, Synth. Commun., 2009, 40, 74-80.

19 Z. J. Wang, C. J. Brown, R. G. Bergman, K. N. Raymond and F. D. Toste, J. Am. Chem. Soc., 2011, 133, 7358-7360.

20 E. Raamat, K. Kaupmees, G. Ovsjannikov, A. Trummal, A. Kütt, J. Saame, I. Koppel, I. Kaljurand, L. Lipping, T. Rodima, V. Pihl, I. A. Koppel and I. Leito, J. Phys. Org. Chem., 2013, 26, 162-170. 